\title{
Abnormal glomerular filtration rate in children, adolescents and young adults starts below $75 \mathrm{~mL} / \mathrm{min} / 1.73 \mathrm{~m}^{2}$
}

\author{
Hans Pottel ${ }^{1}$, Liesbeth Hoste ${ }^{1}$, Pierre Delanaye ${ }^{2}$ \\ ${ }^{1}$ Department of Public Health and Primary Care, Campus Kulak Kortrijk, University of Leuven, Etienne \\ Sabbelaan 53, 8500 Kortrijk, Belgium \\ ${ }^{2}$ Department of Nephrology, Dialysis, Hypertension and Transplantation, University of Liège — CHU Sart \\ Tilman, Liège, Belgium
}

\begin{abstract}
Background The chronic kidney disease (CKD) classification system for children is similar to that for adults, with both mainly based on estimated glomerular filtration rate (eGFR) combined with fixed cut-off values. The main cut-off eGFR value used to define CKD is $60 \mathrm{~mL} / \mathrm{min} / 1.73 \mathrm{~m}^{2}$, a value that is also applied for children older than 2 years of age, adolescents and young adults.

Methods Based on a literature search, we evaluated inclusion criteria for eGFR in clinical trials or research studies on CKD for children. We also collected information on direct measurements of GFR (mGFR) in children and adolescents, with the aim to estimate the normal reference range for GFR. Using serum creatinine (Scr) normal reference values and Scr-based eGFR-equations, we also evaluated the correspondence between Scr normal reference values and (e)GFR normal reference values.

Results Based on our literature search, the inclusion of children in published CKD studies has been based on cutoff values for eGFR of $>60 \mathrm{~mL} / \mathrm{min} / 1.73 \mathrm{~m}^{2}$. The lower reference limits for mGFR far exceed this adult threshold. Using eGFR values calculated using Scr-based formulas, we found that abnormal Scr levels in children already correspond to eGFR values that are below a cut-off of $75 \mathrm{~mL} / \mathrm{min} / 1.73 \mathrm{~m}^{2}$. Conclusions Abnormal GFR in children, adolescents and young adults starts below $75 \mathrm{~mL} / \mathrm{min} / 1.73 \mathrm{~m}$, and as abnormality is a sign of disease, we recommend referring children, adolescents and young adults with an (e)GFR of $<75$ $\mathrm{mL} / \mathrm{min} / 1.73 \mathrm{~m}$ for further clinical assessment.
\end{abstract}

Keywords Glomerular filtration rate Children ; Adolescents ;Young adults ; Cut-off value

\section{Introduction}

Little is known about the epidemiology of chronic kidney disease (CKD) in the paediatric population. Various studies have reported a prevalence of CKD ranging from 12.1 to 74.7 cases per million children [1]. Children who have CKD may present to clinicians with a combination of problems involving growth, nutrition, electrolyte disturbances, renal osteodystrophy, anaemia and hypertension. In these cases renal transplantation follows endstage renal disease (ESRD) often before the patient is 20 years of age. ESRD is a devastating disorder associated with excessive mortality and cardiovascular morbidity. The paediatric ESRD population encounters specific problems, such as impaired growth and psychosocial adjustment, all of which severely impact upon the quality of life [2]. Children requiring dialysis have mortality rates that are 30- to 150-fold higher than the general paediatric population. Therefore, early detection and management of kidney malfunction is crucial to delay or prevent progression of CKD to ESRD [3].

Prior to 2002, the term 'chronic kidney disease' was not used, rather, the term 'chronic renal insufficiency' characterized patients who manifested a progressive decline in renal function. The latter was defined as a glomerular filtration rate (GFR) of $<75 \mathrm{~mL} / \mathrm{min} / 1.73 \mathrm{~m}^{2}$ [4-6]. CKD was defined by the National Kidney Foundation/Kidney Disease and Outcome Quality Initiative (NKF/KDOQI) Group as any patient who has kidney damage lasting for at least 3 months with or without a decreased GFR or any patient who has a GFR of $<60$ $\mathrm{mL} / \mathrm{min} / 1.73 \mathrm{~m}^{2}$ lasting for 3 months with or without kidney damage [7]. The recent international guidelines published in 2012 by KDIGO (Kidney Disease/Improving Global Outcomes) reclassified CKD into six GFR categories, but the key "cut-off' value of $60 \mathrm{~mL} / \mathrm{min} / 1.73 \mathrm{~m}$ remains [8]:

- G1 : Kidney damage with a normal or high GFR $\left(>90 \mathrm{~mL} / \mathrm{min} / 1.73 \mathrm{~m}^{2}\right)$

- G2: Mild reduction in the GFR $\left(60-89 \mathrm{~mL} / \mathrm{min} / 1.73 \mathrm{~m}^{2}\right)$

- G3a: Mild to moderate reduction in the GFR $\left(45-59 \mathrm{~mL} / \mathrm{min} / 1.73 \mathrm{~m}^{2}\right)$

- G3b: Moderate to severe reduction in the GFR (30-44 mL/min/1.73 m )

- G4: Severe reduction in the GFR $\left(15-29 \mathrm{~mL} / \mathrm{min} / 1.73 \mathrm{~m}^{2}\right)$

- G5: Kidney failure (GFR $<15 \mathrm{~mL} / \mathrm{min} / 1.73 \mathrm{~m}^{2}$ or dialysis) 
In the absence of kidney damage (e.g. albuminuria), stage G1 and G2 cannot be considered as CKD; however, stage G3 is always considered as CKD, as only the GFR criterion is then relevant for the CKD diagnosis. In the context of this article, it is important to note that the KDIGO guidelines clearly state that this classification is applicable to paediatric subjects - with the exception children aged $<2$ years $[8,9]$, The GFR values for younger children are actually lower due to ongoing renal maturation [10-12],

As CKD is often asymptomatic in its early stages, it is both underdiagnosed and, as expected, underreported. This is in part the result of the historical absence of a common definition of CKD and a well-defined classification of its severity. Mass screening programs to detect CKD in children have been well established in several Asian countries, such as Kuwait, Japan, Taiwan and Korea [13-16]. Conversely, screening programs have not been adopted in Europe, but urine screening dipsticks have routinely been used in healthy children for decades in the USA. Recent studies suggest that a urine dipstick is not cost-effective in screening children [17], and also the American Academy of Pediatrics recommend discontinuing this screening [18]. There is no doubt that the current CKD classification system described by NKF/KDOQI has increased awareness of the CKD problem in the general population, increased research efforts and stimulated interest in early detection. Retrospective studies based on this CKD definition also try to estimate the importance of CKD in the paediatric population.

A precise and early diagnosis is important to identify preventable or reversible causes of progression, predict prognosis and aid counselling of the children and their families. Screening programs are considered too costly and have therefore been abandoned, but there is now the possibility to automatically obtain an estimated (e)GFR from laboratory data using a height-independent eGFR equation [12], enabling the laboratory to raise an early warning flag. Consequently the choice of the cut-off value for an abnormal GFR is of utmost importance. In this article we present data to justify the choice for normal reference limits for eGFR [or measured GFR (mGFR)] for children, adolescents and young adults.

\section{Methods}

Starting from normal reference intervals of serum creatinine (Scr) for children, we calculated corresponding eGFR limits and compared them with normal reference values for mGFR obtained from literature. We then compared the percentages of children with normal and abnormal Scr with the CKD prevalence obtained from the Pottel equation [12] by applying this equation to a very large hospital database (from General Hospital Groeninge in Kortrijk, Belgium) where only unique patient measurements for enzymatically measured Scr were used. The database has been described in an earlier reported work [19], but we briefly describe it here.

This database contains 317,045 consecutive entries, covering the time periods from mid-2003 up to the end of 2004 and from mid-2005 until the end of 2007 (due to a change in the informatics system of the clinical laboratory, results for the first half year of 2005 could not be retained). The majority of Scr measurements were routinely ordered as part of a basic investigation panel in clinical biochemistry. Consequently most Scr concentrations were expected to be within the so-called normal range. After removal of all patients with serial measurements, we obtained a database of 51,304 observations, including $n=8,505$ observations for children, adolescents and young adults (aged between 2 and 25 years), for which we calculated the median and 2.5th and 97.5th percentiles for different age groups. Data on patients with serial measurements were disregarded because serial measurements are strongly correlated, especially if they were taken consecutively with little time between measurements. The database was seriously reduced by applying this criterion, leaving only one-sixth of the original data for analysis.

For this study, a sub-database was defined for subjects aged between 2 and 25 years. When only the first measurement of each subject was considered, a total of 10,400 subjects were retained. These include the 8,505 subjects with unique Scr values that were used to calculate the median (or Q-value) and 2.5th and 97.5th percentile [19].

A direct GFR measurement is generally unavailable, and the use of so-called estimating equations has therefore been recommended. For children, this is most commonly the Schwartz equation [20] :

$$
\mathrm{eGFR}=0.413 \times \mathrm{L} / \mathrm{Scr}
$$

where L (in $\mathrm{cm}$ ) is the height of the child and Scr is expressed in milligrams per decilitre. This equation requires the height of the subject, which is not commonly included in the clinical record.

We recently presented a new simple height-independent equation to estimate GFR in children [12]: eGFR-Pottel = $107.3 /$ [SCГ/Q],

where $\mathrm{Q}$ is the median Scr concentration of healthy children of a specific age range. We also extended this 
equation to adolescents and young adults, where $\mathrm{Q}$ is a polynomial function of age, i.e. an extension of the linear equation for children [21]. Blufpand et al. independently validated the height-independent eGFR-Pottel equation and concluded that it is a valid alternative to the eGFR-Schwartz formula in children and adolescents and could be used by the laboratory if height data are not available [22],

In the study reported here, all statistical calculations were made in SAS 9.3 (SAS Institute Inc., Cary, NC).

\section{Results}

The frequency distribution according to age, sex and eGFR of all subjects enrolled in this study is presented in Table 1. Table 2 shows the percentage distribution per age period for different cut-off values for eGFR and Scr/Q. Table 3 presents median values (Q) and upper reference limits (URL) for Scr in children, adolescents and young adults (age 2-25 years).

We found that URL/Q acquires a value of approximately 1.33. An example of the Scr and Scr/Q distribution for apparently healthy children aged 7-8 years is shown in Fig. 1, with Fig. la representing a histogram overlaid with the Gaussian distribution, with a mean Scr level of $0.44 \pm 0.067$ (standard deviation) $\mathrm{mg} / \mathrm{dL}$ and Fig. 1b presents the same data for Scr but normalized for $\mathrm{Q}=0.44 \mathrm{mg} / \mathrm{dL}$. Consequently, it follows that the average shifts towards $\mathrm{Scr} / \mathrm{Q}=1$. For the average healthy child, adolescent or young adult, Scr/Q always has a mean of ' 1 ' and an upper reference limit of 1.33 , corresponding to the 97.5 th percentile. This is also illustrated in Fig. 2, where all 8,505 Scr values were normalized by the corresponding age-matched Q-value from Table 3 and plotted all together in one histogram with the overlaid Gaussian distribution. This distribution has a mean of $1.0092 \pm 0.1734$. This demonstrates that by normalizing the Scr values for each age group, the age dependency disappears: Scr/Q is therefore generally applicable (for children, adolescents, and adults) with a mean of 1.00 and URL equal to 1.33

This also means that children, adolescents and young adults with a Scr/Q of > 1.33 have abnormally high Scrvalues. Given this information, it is possible to estimate the effect of Scr/Q on the eGFR. This extreme value of $\mathrm{Scr} / \mathrm{Q}=1.33$ corresponds to an $\mathrm{eGFR}=107.3 / 1.33 \approx 80 \mathrm{~mL} / \mathrm{min} / 1.73 \mathrm{~m}^{2}$. If the eGFR is calculated using this formula for every child in our example of 7- to 8-year-old children, we obtain the eGFR distribution shown in Fig. 1c, which shows both the current CKD cut-off of $60 \mathrm{~mL} / \mathrm{min} / 1.73 \mathrm{~m}^{2}$ and the (e)GFR lower limit of 75 $\mathrm{mL} / \mathrm{min} / 1.73 \mathrm{~m}$. In Fig. 3 we present the eGFR data calculated using the eGFR-Pottel equation (eGFR = 107.3/[Scr/Q]) for all 10,400 children, adolescents and young adults enrolled in our study. This distribution has a mean of $107.6 \pm 17.3 \mathrm{~mL} / \mathrm{min} / 1.73 \mathrm{~m}^{2}$ and a non-parametric 2.5 th percentile of $76.0 \mathrm{~mL} / \mathrm{min} / 1.73 \mathrm{~m}^{2}$.

A child with an Scr/Q of $<1.79$ will have an eGFR of $>107.3 / 1.79=60 \mathrm{~mL} / \mathrm{min} / 1.73 \mathrm{~m}^{2}$. Avalue of Scr/Q between 1.33 and 1.79 is above the normal reference range for Scr, but still that child will have an estimated GFR of $>60 \mathrm{~mL} / \mathrm{min} / 1.73 \mathrm{~m}^{2}$. Such an abnormally high Scr concentration is suspicious and might be an indication of an upcoming or underlying kidney pathology that deserves attention.

An eGFR of $<75 \mathrm{~mL} / \mathrm{min} / 1.73 \mathrm{~m}^{2}$ corresponds with a Scr/ Q of $>1.43$, which is close to an abnormal Scr value (defined as $\mathrm{Scr} / \mathrm{Q}>1.33$ ). As $\mathrm{Scr} / \mathrm{Q}=1.33$ corresponds with the 97.5 th percentile (corresponding to eGFR = 80.67 ), we still expect $2.5 \%$ of healthy children to have an eGFR of $<80.67 \mathrm{~mL} / \mathrm{min} / 1.73 \mathrm{~m}^{2}$. To reduce the false positive rate we propose a cut-off eGFR value of $75 \mathrm{~mL} / \mathrm{min} / 1.73 \mathrm{~m}^{2}$. This lower reference limit for GFR would result in a false positive fraction of $<1 \%$.

\section{Discussion}

Prior to the introduction of the KDIGO classification system, various GFR thresholds were used to diagnose CKD. For example, the ItalKid Project, a prospective, population-based Italian study on CKD epidemiology [5], and the North American Pediatric Renal Trials and Collaborative Studies (NAPRTCS) [6] both defined CKD as an GFR of $<75 \mathrm{~mL} / \mathrm{min} / 1.73 \mathrm{~m}^{2}$. The Chronic Kidney Disease in Children (CKiD) prospective cohort study enrolled 586 children aged between 1 and 16 years with an eGFR ranging from 30 to $90 \mathrm{~mL} / \mathrm{min} / 1.73 \mathrm{~m}^{2}$ [3], of whom 540 children had eGFR of $<75 \mathrm{~mL} / \mathrm{min} / 1.73 \mathrm{~m}^{2}$ [23]. KDIGO refers to the CKiD study as the only largescale study utilizing a validated exogenously measured GFR (iohexol) in a well-described cohort of children with renal disease. The inclusion criterion for GFR was not $60 \mathrm{~mL} / \mathrm{min} / 1.73 \mathrm{~m}^{2}$, but 75 or $90 \mathrm{~mL} / \mathrm{min} / 1.73 \mathrm{~m}$. The GFR was estimated by the Schwartz formula. Other researchers have based their definition on Scr levels (e.g. $>2.0 \mathrm{mg} / \mathrm{dL}$ ) or on other thresholds of GFR (e.g. $<30 \mathrm{~mL} / \mathrm{min} / 1.73 \mathrm{~m}^{2}$ ) $[24,25]$. The KDIGO classification system has, however, been subject to debate. The cut-off value of $60 \mathrm{~mL} / \mathrm{min} / 1.73 \mathrm{~m}^{2}$ defined in 2002 by a KDOQI panel of experts is based upon a level that is $50 \%$ of the average mGFR for 20 year-old adults [7]. This highly arbitrary, disease-defining, fixed CKD diagnostic threshold for a 20-year-old is mathematically attractive ( $50 \%$ of the norm) but not epidemiologically sound [26, 27]. The value of $75 \mathrm{~mL} / \mathrm{min} / 1.73 \mathrm{~m}^{2}$ used for children in the above-mentioned studies is based on broad clinical experience and is probably more scientifically sound 
than the arbitrary choice of one-half of $120 \mathrm{~mL} / \mathrm{min} / 1.73 \mathrm{~m}^{2}$, as no true rationale for that value was available at that time.

The availability of reference values of mGFR for children is scarce. The most important and most referenced article is that of Piepsz et al. who published normal reference intervals for ${ }^{51} \mathrm{Cr}$-EDTA [28] for children aged $>2$ years, with a mean $( \pm \mathrm{SD})$ of $104.4 \pm 19.9 \mathrm{~mL} / \mathrm{min} / 1.73 \mathrm{~m}^{2}$. These authors reported a 10th and 90th percentile of 81 and $135 \mathrm{~mL} / \mathrm{min} / 1.73 \mathrm{~m}^{2}$ respectively. Assuming normal (Gaussian) distributions, with a 10th percentile of 81 , the corresponding 2.5 th percentile equals $69 \mathrm{~mL} / \mathrm{min} / 1.73 \mathrm{~m}^{2}$. Blake et al. [29] reported a mean mGFR of $107 \pm 17 \mathrm{~mL} / \mathrm{min} / 1.73 \mathrm{~m}^{2}$; based on this result, the corresponding 2.5 th percentile equals $74 \mathrm{~mL} / \mathrm{min} / 1.73 \mathrm{~m}^{2}$. Heilbron et al. [30] reported a GFR range of $89-165 \mathrm{~mL} / \mathrm{min} / 1.73 \mathrm{~m}^{2}$ for 2- to 12 -year-old healthy children. In their study of children aged $>2$ years with solid tumours, Brandt et al. [31] reported a mean GFR of 131.5 \pm 22.5 $\mathrm{mL} / \mathrm{min} / 1.73 \mathrm{~m}^{2}$ for males and $126.8 \pm 24.4 \mathrm{~mL} / \mathrm{min} / 1.73 \mathrm{~m}^{2}$ for females. Using the normal approximation, we were able to calculate the 2.5 th percentiles from these mean values $( \pm$ SD) to obtain values of 86 and 78 $\mathrm{mL} / \mathrm{min} / 1.73 \mathrm{~m}^{2}$, respectively. Fadrowski and Furth [32] presented mean ranges for mGFR obtained via inulin clearance in adolescents without kidney disease of $112 \pm 13$ to $117 \pm 16 \mathrm{~mL} / \mathrm{min} / 1.73 \mathrm{~m}^{2}$. Based on these values, obtained from relatively small studies, the GFR would be expected to range from approximately 85 to 150 $\mathrm{mL} / \mathrm{min} / 1.73 \mathrm{~m}^{2}$ in $95 \%$ of healthy adolescents. Fadrowski and Furth [32] concluded that it is not yet possible to define a 'normal' eGFR cut-off using the CKiD equations, but it is likely that the cut-off is $<90 \mathrm{~mL} / \mathrm{min} / 1.73 \mathrm{~m}$. Based on the above cited literature, the 'normal' GFR cut-off is also likely to be $>60 \mathrm{~mL} / \mathrm{min} / 1.73 \mathrm{~m}^{2}$.

The most used eGFR equation for children is the Schwartz-equation (eGFR $=0.413 \mathrm{~L} / \mathrm{Scr}$ ). Our equation of $\mathrm{eGFR}=107.3 /[\mathrm{Scr} / \mathrm{Q}]$ can be seen as an alternative way of expressing the Schwartz equation, as a linear relationship exists between $\mathrm{Q}$ and height for children: $\mathrm{Q}=0.0035 \times \mathrm{L}$ (in $\mathrm{cm})\left(R^{2}=0.975\right.$ with $76 \mathrm{~cm}<\mathrm{L}<166$ $\mathrm{cm}$ ) [21]. Using this linear equation for $\mathrm{Q}$, our equation becomes eGFR $=0.376 \mathrm{~L} / \mathrm{Scr}$, which is close to the wellknown Schwartz equation. This value of 0.376 is also the average in children in the age range of 1-14 years of $k$ $0.0414 \times \ln ($ age $)+0.3018$, being the age-dependent $k$-value in the Flanders Metadata equation [11],

We have shown in the Results section that the upper reference value of Scr/Q $=1.33$ is also valid for adolescents and young adults. Therefore, $\mathrm{eGFR}=80.67 \mathrm{~mL} / \mathrm{min} / 1.73 \mathrm{~m}^{2}$ also corresponds to the upper limit for Scr for these subjects. The CKD-EPI equation [33] has been validated for adults between 18 and 65 years. The upper limit of Scr for young male adults and young female adults is 1.16 and $0.93 \mathrm{mg} / \mathrm{dL}$, respectively (Table 3).

The corresponding value for eGFR at age 18 years is therefore:

$$
\begin{gathered}
\mathrm{eGFR}=141 \times(1.16 / 0.90)^{-1.209} 0.993^{18} \\
=91 \mathrm{~mL} / \mathrm{min} / 1.73 \mathrm{~m}^{2} \text { for young adult males, and } \\
\mathrm{eGFR}=141 \times(0.93 / 0.70)^{-1.209} 0.993^{18}=90 \mathrm{~mL} / \mathrm{min} / 1.73 \mathrm{~m}^{2}
\end{gathered}
$$

for young adult females

In comparison, the MDRD equation [34] obtains 82 and $79 \mathrm{~mL} / \mathrm{min} / 1.73 \mathrm{~m}^{2}$ for the corresponding Scr values in males and females, respectively.

Based on this reasoning, it is very possible that many children, adolescents and young adults may have an Scr value that falls far outside (above) the normal range, but without having an eGFR that falls below the current CKD cut-off of $60 \mathrm{~mL} / \mathrm{min} / 1.73 \mathrm{~m}^{2}$. This is clearly demonstrated in the example shown in Fig. 1.

A young adolescent boy of 18 years old would need an Scr value of $1.65 \mathrm{mg} / \mathrm{dL}$ (which is more than 1.8 -fold higher than the average of $0.90 \mathrm{mg} / \mathrm{dL}$ for healthy young males at this age and far above the normal upper reference value of $1.16 \mathrm{mg} / \mathrm{dL}$ ) before he would reach the eGFR cut-off value of $60 \mathrm{~mL} / \mathrm{min} / 1.73 \mathrm{~m}^{2}$ for CKD based on the CKD-EPI equation. This same value of $1.65 \mathrm{mg} / \mathrm{dL}$ for Scr results in the same eGFR prediction when the eGFR value is based on eGFR equations for children and adolescents: eGFR =107.3/[1.65/0.90] = 59 $\mathrm{mL} / \mathrm{min} / 1.73 \mathrm{~m}^{2}$. These values demonstrate that Scr raises a much earlier warning flag than eGFR- solely because of the arbitrary threshold of $60 \mathrm{~mL} / \mathrm{min} / 1.73 \mathrm{~m}^{2}$, which is much too low for children, adolescents and young adults.

In 2011, we proposed a simple classification system for CKD based on the Scr/Q value for adults [35]. This classification system uses $\mathrm{Scr} / \mathrm{Q}=1.5$ to define CKD stage G3a, corresponding to eGFR $=107.3 / 1.5=71.5$ $\mathrm{mL} / \mathrm{min} / 1.73 \mathrm{~m}^{2}$. Using the CKD-EPI equation for 20 year-old young adults, with $\mathrm{Scr} / 0.9=\mathrm{Scr} / 0.7=1.5$ for males and females, respectively we obtain a corresponding eGFR $\approx 5 \mathrm{~mL} / \mathrm{min} / 1.73 \mathrm{~m}^{2}$.

With respect to the limitations of our study, it is important to note that we are aware that the vast majority of children with CKD stage G2 have either structural abnormalities or markers of kidney damage (urine sediment or electrolyte abnormalities), as the most common pathologies are congenital anomalies of kidney and urinary tract (CAKUT) and glomerulonephritis. Sensu stricto, the CKD status is reached when structural abnormalities are 
present. However, there is no doubt that the level of GFR is important and will impact the choices made by nephrologists with respect to therapeutic approach and subsequent treatment of patients.

Table 1: Frequency distribution of the 10,400 children, adolescents and young adults comprising the study cohort according to sex and estimated glomerular filtration rate (eGFR) calculated using the eGFR-Pottel equation $^{3}$

\begin{tabular}{|c|c|c|c|c|c|c|c|c|}
\hline \multirow[t]{2}{*}{ Age of subjects } & \multirow[t]{2}{*}{ Sex } & $\mathrm{eGFF}$ & \multicolumn{6}{|c|}{$\left(\mathrm{mL} / \mathrm{min} / 1.73 \mathrm{~m}^{2}\right)$} \\
\hline & & $<30$ & $30-60$ & $60-90$ & $90-120$ & $120-150$ & $>150$ & Total \\
\hline \multirow[t]{2}{*}{ Children (2-14 years) } & Female & 0 & 7 & 286 & 1,310 & 507 & 77 & 2,187 \\
\hline & Male & 2 & 11 & 304 & 1,362 & 551 & 84 & 2,314 \\
\hline \multirow[t]{2}{*}{ Adolescents (14-18 years) } & Female & 2 & 2 & 112 & 562 & 171 & 14 & 863 \\
\hline & Male & 2 & 1 & 94 & 435 & 126 & 21 & 679 \\
\hline \multirow{2}{*}{$\begin{array}{l}\text { Young adults (18-25 } \\
\text { years) }\end{array}$} & Female & 1 & 6 & 267 & 1,449 & 641 & 169 & 2,533 \\
\hline & Male & 4 & 5 & 322 & 1,144 & 314 & 35 & 1,824 \\
\hline \multirow[t]{2}{*}{ Total } & Female & 3 & 15 & 665 & 3,321 & 1,319 & 260 & 5,583 \\
\hline & Male & 8 & 17 & 720 & 2,941 & 991 & 140 & 4,817 \\
\hline
\end{tabular}

Data are presented as the number of subjects

${ }^{\mathrm{a}}$ eGFR-Pottel $=107.3 /[\mathrm{Scr} / \mathrm{Q}]$, where $\mathrm{Q}$ is the median serum creatinine $(\mathrm{Scr})$ concentration of healthy children of a specific age range

Table 2: Frequency distribution ${ }^{3}$ of the 10,400 children, adolescents and young adults comprising the study cohort according to different cut-off values and age periods

\begin{tabular}{|c|c|c|c|c|c|}
\hline $\begin{array}{l}\text { Age range } \\
\text { (years) }\end{array}$ & $\begin{array}{l}\mathrm{Scr} / \mathrm{Q}>1.79 ; \mathrm{eGFR}<60 \\
\mathrm{~mL} / \mathrm{min} / 1.73 \mathrm{~m}\end{array}$ & $\begin{array}{l}\mathrm{Scr} / \mathrm{Q}>1.43 ; \mathrm{eGFR}<75 \\
\mathrm{~mL} / \mathrm{min} / 1.73 \mathrm{~m}\end{array}$ & $\begin{array}{l}\mathrm{Scr} / \mathrm{Q}>1.33 ; \text { eGFR < } \\
80.67 \mathrm{~mL} / \mathrm{min} / 1.73 \mathrm{~m}\end{array}$ & $\begin{array}{l}\mathrm{Scr} / \mathrm{Q}<1.33 ; \mathrm{eGFR}>80.67 \\
\mathrm{~mL} / \mathrm{min} / 1.73 \mathrm{~m}\end{array}$ & $n$ \\
\hline $2-3$ & 0.34 & 1.83 & 4.58 & 95.42 & 873 \\
\hline $3-4$ & 0.14 & 2.09 & 4.59 & 95.41 & 719 \\
\hline $4-5$ & 0.65 & 2.61 & 5.01 & 94.99 & 459 \\
\hline $5-6$ & 0.26 & 2.11 & 5.00 & 95.00 & 380 \\
\hline $6-7$ & 0.00 & 3.65 & 6.98 & 93.02 & 301 \\
\hline $7-8$ & 0.72 & 3.24 & 5.04 & 94.96 & 278 \\
\hline $8-9$ & 0.00 & 2.16 & 4.33 & 95.67 & 231 \\
\hline $9-10$ & 0.39 & 3.91 & 6.25 & 93.75 & 256 \\
\hline $10-11$ & 0.38 & 1.90 & 3.80 & 96.20 & 263 \\
\hline $11-12$ & 1.22 & 2.45 & 2.86 & 97.14 & 245 \\
\hline $12-13$ & 2.02 & 2.02 & 4.03 & 95.97 & 248 \\
\hline $13-14$ & 0.00 & 3.23 & 4.84 & 95.16 & 248 \\
\hline $14-15$ & 0.36 & 1.44 & 2.17 & 97.83 & 277 \\
\hline $15-16$ & 0.58 & 2.02 & 5.48 & 94.52 & 347 \\
\hline $16-17$ & 0.46 & 2.30 & 4.60 & 95.40 & 435 \\
\hline $17-18$ & 0.41 & 1.86 & 3.31 & 96.69 & 483 \\
\hline $18-19$ & 0.00 & 0.80 & 2.19 & 97.81 & 502 \\
\hline $19-20$ & 0.33 & 0.99 & 2.80 & 97.20 & 607 \\
\hline $20-25$ & 0.31 & 1.51 & 3.26 & 96.74 & 3,248 \\
\hline Total & 0.38 & 1.91 & 3.94 & 96.06 & 10,400 \\
\hline
\end{tabular}

\footnotetext{
${ }^{a}$ Data in table are presented as the percentage distribution
} 
Table 3: Mean or median serum creatinine concentration and upper reference limit for normal children in different age ranges

\begin{tabular}{lllll}
$\begin{array}{l}\text { Age range } \\
\text { (years) }\end{array}$ & $n$ & $\begin{array}{l}\text { Median (Q- } \\
\text { value) }\end{array}$ & URL & URL/Q \\
\hline All children & & & & \\
$2-3$ & 743 & 0.29 & 0.42 & 1.45 \\
$3-4$ & 629 & 0.33 & 0.44 & 1.33 \\
$4-5$ & 419 & 0.36 & 0.49 & 1.36 \\
$5-6$ & 329 & 0.38 & 0.51 & 1.34 \\
$6-7$ & 279 & 0.42 & 0.55 & 1.31 \\
$7-8$ & 252 & 0.44 & 0.58 & 1.32 \\
$8-9$ & 216 & 0.46 & 0.62 & 1.35 \\
$9-10$ & 220 & 0.49 & 0.65 & 1.33 \\
$10-11$ & 239 & 0.52 & 0.67 & 1.29 \\
$11-12$ & 205 & 0.53 & 0.70 & 1.32 \\
$12-13$ & 201 & 0.57 & 0.75 & 1.32 \\
$13-14$ & 201 & 0.61 & 0.81 & 1.33 \\
Females & & & & \\
$14-15$ & 111 & 0.62 & 0.81 & 1.31 \\
$15-16$ & 180 & 0.67 & 0.86 & 1.28 \\
$16-17$ & 182 & 0.70 & 0.91 & 1.30 \\
$17-18$ & 198 & 0.70 & 0.93 & 1.33 \\
$18-25$ & 1,949 & 0.70 & 0.93 & 1.33 \\
Males & & & & \\
$14-15$ & 104 & 0.67 & 0.89 & 1.33 \\
$15-16$ & 94 & 0.78 & 1.02 & 1.31 \\
$16-17$ & 149 & 0.81 & 1.07 & 1.32 \\
$17-18$ & 166 & 0.85 & 1.09 & 1.28 \\
$18-25$ & 1,439 & 0.90 & 1.16 & 1.29 \\
& & & Mean & 1.33 \\
& & & $S D$ & 0.04 \\
URL, Uppen & & & &
\end{tabular}

URL, Upper reference limit 
Fig. 1 a Frequency distribution of the serum creatinine ( $S c r)$ concentration with an overlaid Gaussian probability density function for 253 healthy children aged between 7 and 8 years, b Frequency distribution of the normalized Scr ( $\mathrm{Scr}$ is divided by $\mathrm{Q}=0.44 \mathrm{mg} / \mathrm{dL}$, where $\mathrm{Q}$ is the median Scr concentration of healthy children of the 7-8 year age range) with an overlaid Gaussian probability density function for the same subgroup of children as in Fig. 1a. c Frequency distribution of estimated glomerular filtration rate $(e G F R)$ estimated using the eGFR-Pottel equation (eGFR $=107.3 /[\mathrm{Scr} / \mathrm{Q}]$ ) with an overlaid Gaussian probability density function for the same Scr data as in Fig. 1a, b. Left vertical line eGVR cut-off at $60 \mathrm{~mL} / \mathrm{min} / 1.73 \mathrm{~m}^{2}$, right vertical line lower reference limit of 75 $\mathrm{mL} / \mathrm{min} / 1.73 \mathrm{~m}^{2}$
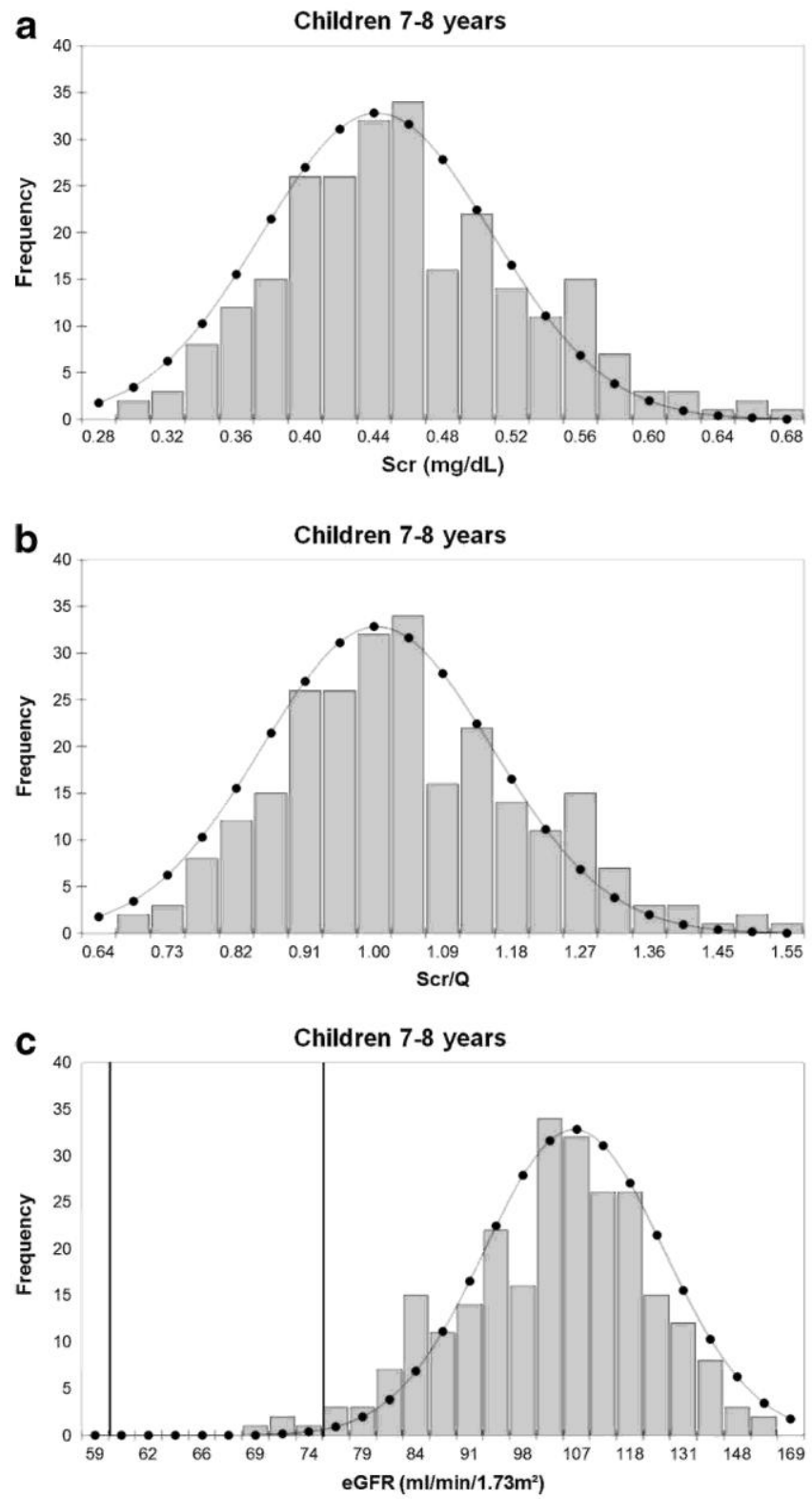
Fig. 2 Distribution of $\mathrm{ScrN}=\mathrm{Scr} / \mathrm{Q}$ for in 8,505 children, adolescents and young adults (<25 years of age). The distribution has a mean of $1.0092 \mathrm{mg} / \mathrm{dL}$ and a standard deviation (SD) of $0.1734 \mathrm{mg} / \mathrm{dL}$. The non-parametric 2.5th and 97.5 th percentile are 0.69 and $1.39 \mathrm{mg} / \mathrm{dL}$, respectively. Based on the normal distribution, the predicted 2.5 th and 97.5 th percentile are 0.67 and $1.35 \mathrm{mg} / \mathrm{dL}$, respectively

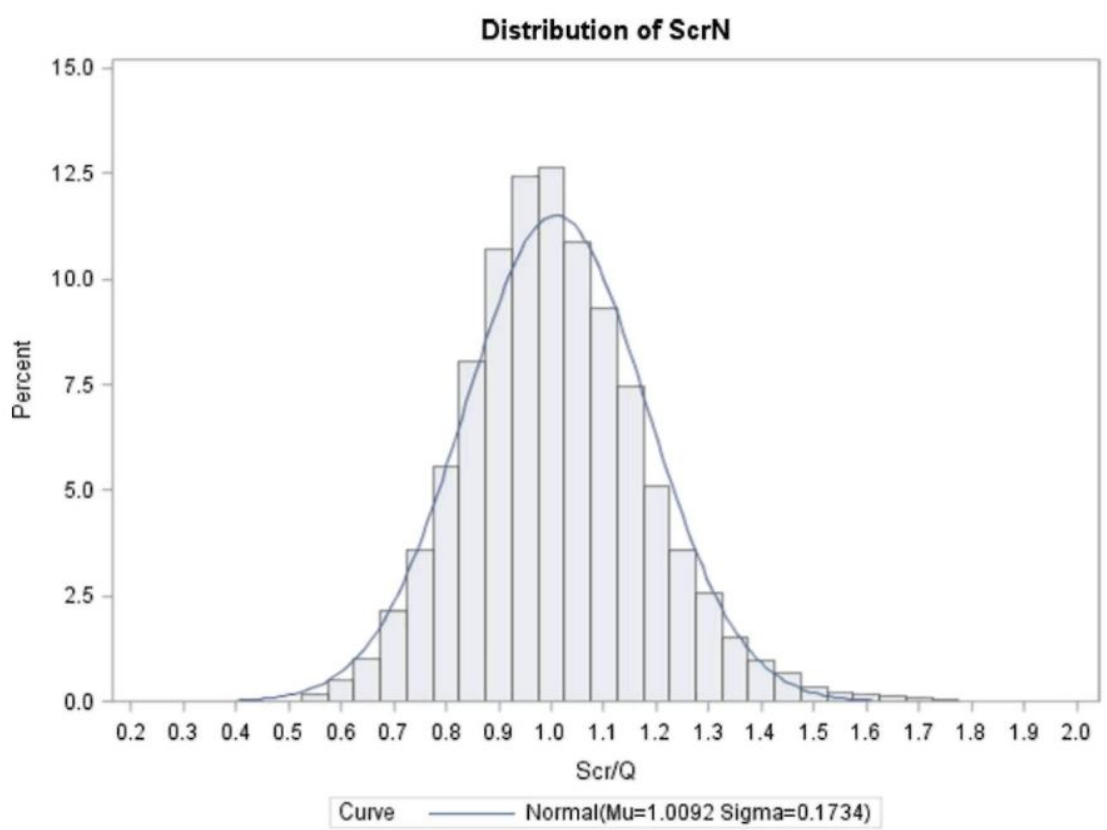

Fig. 3 Distribution of eGFR calculated using the eGFR-Pottel equation (eGRF =107.3/[Scr/Q]) for 10,400 children, adolescents and young adults $(<25$ years of age). The distribution has a mean of $107.6 \pm 17.3$ $\mathrm{mL} / \mathrm{min} / 1.73 \mathrm{~m}^{2}$. The non-parametric 2.5 th percentile for this distribution is $76 \mathrm{~mL} / \mathrm{min} / 1.73 \mathrm{~m}^{2}$. Based on the normal distribution, the predicted 2.5 th percentile is $74 \mathrm{~mL} / \mathrm{min} / 1.73 \mathrm{~m}^{2}$

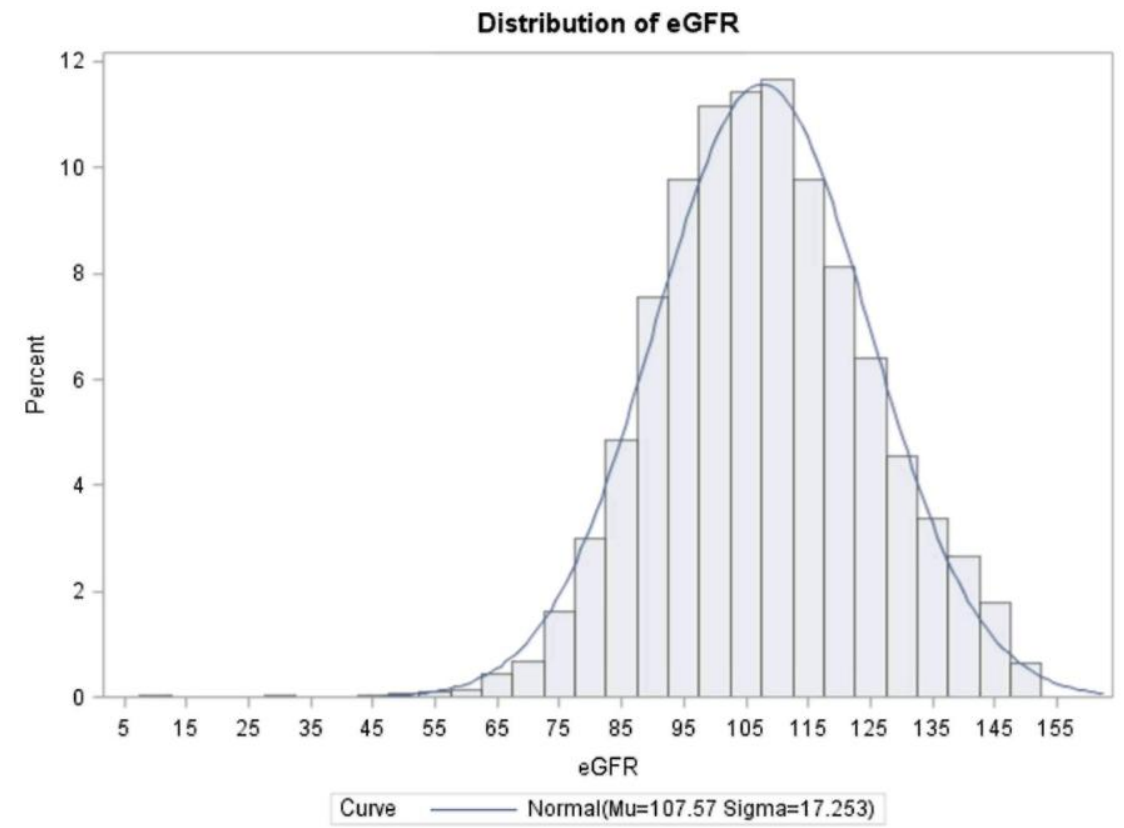




\section{Conclusion}

Based on the arguments presented in this article (clinical experience, reference values of mGFR, lower limits for eGFR calculated from upper limits of Scr levels), it is clear that the lower limit for (e)GFR for children, adolescents and young adults equals $75 \mathrm{~mL} / \mathrm{min} / 1.73 \mathrm{~m}^{2}$. Based on the currently used cut-off of $60 \mathrm{~mL} / \mathrm{min} / 1.73$ $\mathrm{m}^{2}$ in the CKD classification system and in cases where there are no other signs of kidney malfunction, a fraction of subjects with abnormal Scr values, and thus with abnormally low eGFR ( $\left.<75 \mathrm{~mL} / \mathrm{min} / 1.73 \mathrm{~m}^{2}\right)$, will not be referred to the nephrologist within an acceptable time span. We therefore encourage the utilization of heightindependent eGFR predictions combined with a cut-off value of $75 \mathrm{~mL} / \mathrm{min} / 1.73 \mathrm{~m}^{2}$ as an early warning flag in the clinical laboratory report. The nephrologist still needs to make the definite diagnosis for these children. eGFR reporting combined with the eGFR cut-off of $75 \mathrm{~mL} / \mathrm{min} / 1.73 \mathrm{~m}^{2}$ will help in identifying children, adolescents and young adults 'at risk' for progression towards CKD. Prospective studies are needed to determine whether asymptomatic children 'at risk' (with eGFR of $<75 \mathrm{~mL} / \mathrm{min} / 1.73 \mathrm{~m}^{2}$ ) indeed progress towards CKD.

\section{References}

1. Warady BA, Chadha V (2007) Chronic kidney disease in children: the global perspective. Pediatr Nephrol 22:1999-2009

2. Harambat J, van Stralen KJ, Kim JJ, Tizard EJ (2012) Epidemiology of chronic kidney disease in children. Pediatr Nephrol 27:363-373

3. Wong CJ, Moxey-Mims M, Jerry-Fluker J, Warady BA, Furth SL (2012) CKiD (CKD in Children) prospective cohort study: a review of current findings. Am J Kidney Dis 60:1002-1011

4. Whyte DA, Fine RN (2008) Chronic kidney disease in children. Pediatr Rev 29:335-341

5. ItalKid Project, Ardissino G, Dacco V, Testa S, Bonaudo R, Claris-Appiani A, Taioli E, Marra G, Edefonti A, Sereni F (2003) Epidemiology of chronic renal failure in children: data from the ItalKid project. Pediatrics 111:e382-e387

6. Fivush BA, Jabs K, Neu AM, Sullivan EK, Feld L, Kohaut E, Fine R (1998) Chronic renal insufficiency in children and adolescents: the 1996 annual report of NAPRTCS. North American Pediatric Renal Transplant Cooperative Study. Pediatr Nephrol 12:328-337

7. National Kidney Foundation (2002) K/DOQI clinical practice guidelines for chronic kidney disease: evaluation, classification, and stratification. Am J Kidney Dis 39:S1-S266

8. Kidney Disease: Improving Global Outcomes (KDIGO) (2013) KDIGO 2012 Clinical practice guideline for the evaluation and management of chronic kidney disease. Kidney Int Suppl 3:1-150

9. National Kidney Foundation's Kidney Disease Outcomes Quality Initiative, Hogg RJ, Furth S, Lemley KV, Portman R, Schwartz GJ, Coresh J, Balk E, Lau J, Levin A, Kausz AT, Eknoyan G, Levey AS (2003) National Kidney Foundation's Kidney Disease Outcomes Quality Initiative clinical practice guidelines for chronic kidney disease in children and adolescents: evaluation, classification, and stratification. Pediatrics 111:1416-1421

10. Hayton WL (2000) Maturation and growth of renal function: dosing renally cleared drugs in children. AAPS PharmSci 2:22-28

11. Pottel H, Mottaghy FM, Zaman Z, Martens F (2010) On the relationship between glomerular filtration rate and serum creatinine in children. Pediatr Nephrol 25:927-934

12. Pottel H, Hoste L, Martens F (2012) A simple height-independent equation for estimating glomerular filtration rate in children. Pediatr Nephrol 27:973-979

13. Al-Eisa A, Naseef M, Al-Hamad N, Pinto R, Al-Shimeri N, Tahmaz M (2005) Chronic renal failure in Kuwaiti children: an eight-year experience. Pediatr Nephrol 20:1781-1785

14. Murakami M, Hayakawa M, Yanagihara T, Hukunaga Y (2005) Proteinuria screening for children. Kidney Int Suppl 94:S23-27

15. Lin CY, Sheng CC, Chen CH, Lin CC, Chou P (2000) The prevalence of heavy proteinuria and progression risk factors in children undergoing urinary screening. Pediatr Nephrol 14:953-959

16. Cho BS, Kim SD (2007) School urinalysis screening in Korea. Nephrology (Carlton) 12:S3-S7

17. Sekhar DL, Wang L, Hollenbeak CS, Widome MD, Paul IM (2010) A cost-effectiveness analysis of screening urine dipsticks in wellchild care. Pediatrics 125:660-663

18. Committee on Practice and Ambulatory Medicine and Bright Futures Steering Committee (2007) Recommendations for preventive pediatric health care. Pediatrics 120:1376

19. Pottel H, Vrydags N, Mahieu B, Vandewynckele E, Croes K, Martens F (2008) Establishing age/sex related serum creatinine reference intervals from hospital laboratory data based on different statistical methods. Clin Chim Acta 396:49-55

20. Schwartz GJ, Munoz A, Schneider MF, Mak RH, Kaskel F, Warady BA, Furth SL (2009) New equations to estimate GFR in children with CKD. J Am Soc Nephrol 20:629-637

21. Hoste L, Dubourg L, Selistre L, De Souza VC, Ranchin B, Hadj-Aissa A, Cochat P, Martens F, Pottel H (2014) A new equation to estimate the glomerular filtration rate in children, adolescents and young adults. Nephrol Dial Transplant 29:1082-1091

22. Blufpand HN, Westland R, van Wijk JA, Roelandse-Koop EA, Kaspers G J, Bokenkamp A (2013) Height-independent estimation of glomerular filtration rate in children: an alternative to the Schwartz equation. J Pediatr 163:1722-1727

23. Furth SL, Cole SR Moxey-Mims M, Kaskel F, Mak R, Schwartz G, Wong C, Munoz A, Warady BA (2006) Design and methods of the 
Published in: Pediatric Nephrology: Journal of the International Pediatric Nephrology Association (2015), vol. 30, pp. 821-828

Status: Postprint (author's version)

Chronic Kidney Disease in Children (CKiD) prospective cohort study. Clin J Am Soc Nephrol 1:1006-1015

24. Deleau J, Andre JL, Briancon S, Musse JP (1994) Chronic renal failure in children: an epidemiological survey in Lorraine (France) 1975-1990. Pediatr Nephrol 8:472-476

25. Esbjorner E, Berg U, Hansson S (1997) Epidemiology of chronic renal failure in children: a report from Sweden 1986-1994. Swedish Pediatric Nephrology Association. Pediatr Nephrol 11:438-442

26. Glas sock RJ (2014) Con: Thresholds to define chronic kidney disease should not be age dependent. Nephrol Dial Transplant 29:774-779

27. Delanaye P, Schaeffher E, Ebert N, Cavalier E, Mariat C, Krzesinski JM, Moranne O (2012) Normal reference values for glomerular filtration rate: what do we really know? Nephrol Dial Transplant 27:2664-2672

28. Piepsz A, Tondeur M, Ham H (2006) Revisiting normal (51)Cr-ethylenediaminetetraacetic acid clearance values in children. Eur J Nucl Med Mol Imaging 33:1477-1482

29. Blake GM, Gardiner N, Gnanasegaran G, Dizdarevic S (2005) Reference ranges for 51Cr-EDTA measurements of glomerular filtration rate in children. Nucl Med Commun 26:983-987

30. Heilbron DC, Holliday MA, al-Dahwi A, Kogan BA (1991) Expressing glomerular filtration rate in children. Pediatr Nephrol 5:5-11

31. Brandt JR, Wong C, Jones DR Quails C, McAfee N, Brewer E, Watkins SL (2003) Glomerular filtration rate in children with solid tumors: normative values and a new method for estimation. Pediatr Hematol Oncol 20:309-318

32. Fadrowski JJ, Furth SL (2011) GFR estimation in children: questions and answers (and questions). Clin J Am Soc Nephrol 6:1810-1812

33. Levey AS, Stevens LA, Schmid CH, Zhang YL, Castro AF 3rd, Feldman HI, Kusek JW, Eggers P, Van Lente F, Greene T, Coresh J (2009) A new equation to estimate glomerular filtration rate. Ann Intern Med 150:604-612

34. Levey AS, Coresh J, Greene T, Marsh J, Stevens LA, Kusek JW, Van Lente F (2007) Expressing the Modification of Diet in Renal Disease Study equation for estimating glomerular filtration rate with standardized serum creatinine values. Clin Chem 53:766-772

35. Pottel H, Hoste L, Martens F (2011) Chronic Kidney Disease Classification: a simple proposal. Eur Nephrol 5:10-14 